$\underline{\text { Session } 3255}$

\title{
Industry Needs: Engineering Graduate Program Opportunities
}

\author{
Mark L. Crozier \\ University of St. Thomas
}

America has been the benchmark for technological innovation for over a century ${ }^{1}$. America's expertise with advancing a concept from initial thought to reality has been evident since the dawning of the Industrial Revolution, through designs and advancements in automated manufacturing technology, and the dawning of a computerized world culture. The most significant recognizable catalyst facilitating the transition of a concept to physical reality is the Engineering discipline. The American Heritage dictionary (1976) defines the Engineering discipline as "The application of scientific principles to practical ends as the design, construction and operation of efficient and economical structures, equipment, and systems." It would be quite presumptuous to propose or even imply that American engineering capabilities by themselves are more advanced or highly regarded than another country's or civilization's. A cursory review of industrial history would illustrate an endless accounting of engineering marvels spanning the world's civilizations. What appears to set one engineering function apart from another is the ability to establish itself as a core competency while integrating with supporting business activities associated with a production or service operations.

Given the hypothesis that U.S. engineering disciplines are on par with engineering activities in other industrialized countries, one may then assume that a decisive factor contributing to the advancement of one technology over another is this ability for complete, comprehensive integration with supporting functions noted earlier. Therein lies the crux of this paper's argument. Over the past twenty years there has been a growing concern the U.S. is rapidly losing its status as an industrial benchmark. Newspapers periodically contribute articles noting the erosion of traditional American "power" industries such as automobile design and production, space technology, petroleum and chemical production, etc. to foreign bases. A point gleaned from research articles on such studies is that perhaps the U.S. hasn't lost what it had with regard to industrial capabilities so much as other countries have finally caught up ${ }^{2}$. Industrial parity is being achieved worldwide. Conditions have begun to form that require an "evolution to the next step" for regaining and maintaining an industrial benchmark. This point in the industrial evolution process appears to provide an opportunity for the Engineering discipline to redefine and reestablish its standard for excellence.

Proceedings of the 2001 American Society for Engineering Education Annual Conference \& Exposition Copyright (C) 2001, American Society for Engineering Education 
Traditional engineering core competencies centered on mathematical and scientific principles by themselves are no longer adequate to meet industry needs. Professional Engineers are becoming increasingly involved as team members tasked to aggressively execute a given strategy or tactical requirement. Engineering disciplines are increasingly being called upon to function as part of a cross - functional group. Businesses are evolving their organizational matrices from traditional hierarchical configurations to functional departmental integration. Companies infrastructures are evolving from stand-alone entities, or "businesses within a business" to wholly integrated departments with no discernable lines of separation ${ }^{3}$. This change in functional structure and the accompanying culture shift introduces opportunities for a given organization to learn new techniques or methodologies that traditionally may have been addressed by other areas either internally or externally. The focus is toward continuously improving efficiencies for increased margins of competitiveness.

To the engineering world this means adding new tools to the old toolbox. The automobile industry and medical device industry are two of several evolving technologies that have demonstrated the value of two engineering-based subjects that have yet to be adopted across the engineering spectrum. The Failure Mode \& Effect Analysis (FMEA) process ${ }^{4}$ and Design of Experiments analytical mathematics ${ }^{5}$ are just two process tools making their appearance within America's technical development arena within the last twenty years. Their applications are to enhance robust product and / or process design thereby increasing product / process reliability and manufacturability. While these two tools are not new to the industrial world, their usage by most U.S. engineering disciplines has been for the most part relegated to specialists or "the Quality guys." Operating in a cross-functional team environment, engineering staff are being called upon with increased frequency to perform pre-production failure probability studies and / or post-mortem analysis of material failures. The intent is to learn from an analysis and then implement design improvements focused on root cause. Business has learned this can be a very expensive learning process. The Japanese, and to a limited degree American production industries, have demonstrated the benefits gained when engineering personnel have integrated such analytical methodologies into their design and test processes before product is released for production or to a customer.

Quality Function Deployment ${ }^{6}$ (QFD) is a third process demonstrated as an effective planning process used to capture the spectrum of customer needs and requirements (both internal and external to the given business) at the front end of the design process. Cost accounting research over the years has demonstrated that the number of dollars invested in proper engineering analysis at the beginning of a project (through techniques such as QFD) are more palatable to a business than dollars spent rectifying a problem once a design or product has been released. Utilizing QFD applications requires cross-functional communication of all internal and external players involved with development and production of a given product or process. Here again, human relation skills associated with program and project management activities are a must for the engineer functioning in this arena.

Opportunities are becoming increasingly obvious for engineers to come equipped with the ability to work through cross-functional team dynamics and have a sound level of knowledge of design and / or product configuration and data management practices ${ }^{7}$. The need to protect and secure a

Proceedings of the 2001 American Society for Engineering Education Annual Conference \& Exposition Copyright (C) 2001, American Society for Engineering Education 
company's interest through a given product or process design and usage against copyright infringement or liability risks opens opportunities to fortify the engineer's toolbox with some basic configuration management tools. At this point, one should recognize that the term "tools" applies to practical knowledge as well as to a physical entity. Document and product configuration management accountabilities are perhaps the "soft spot," if you will, of an engineering discipline. Typically configuration management systems are "tailor made" to fit a given company's engineering program. Oft times document, drawing and / or product configuration management discipline slips due to product delivery priorities. A thorough understanding of the intent of configuration management practices is essential to insure the correct level of information is available to users to preclude not only liability and legal issues but costly product nonconformance control activities. The core intent or basic requirements as they are applied to any document or product configuration management system needs to be understood by engineering personnel. Shortcomings in these two areas of administrative discipline have a potential negative impact on all other aspects of the company's systems supported by engineering.

Perhaps this is a good point to reflect on the role engineering operations and personnel play within an organization. As noted earlier, traditional concepts and practices of "stand-alone" departments or functions is rapidly disappearing. Internal business disciplines (including engineering operations) are being driven to interact across traditional lines of "performance ownership." This change in operational practice and culture establishes a heightened level of awareness with everyone working as a pool, actively assisting and addressing issues across what was once established as territorial lines of business. A result of this transformation is a much quicker realization of results from a given action (or decision) or set of actions. Engineers from today's education pipeline remain able to adequately address basic technical issues as their contribution to a team's solution for a given problem. This is to say they can address a limited scope of problem solving requirements. Teaming activities employed by companies to drive changes at a quicker pace are demanding more than traditional quantitative analysis and hypothesis testing from engineers. Engineering contributions to an overall effort is greatly enhanced when project management skills are introduced into an engineer's repertoire of problem solving skills. Proficiency with project management skills affords the engineer a more effective position as a change agent. Familiarity and practical experience with tools such as Affinity Diagrams, Interrelationship Digraphs, Matrix Data Analysis Charts, Tree Diagrams, Activity Network Diagrams and Process Decision Program Charts demonstrate the people skills and decision-making abilities that allow the engineer to effectively draw his (or her) technical skills into a team problem-solving scenario thereby providing a comprehensive quantitative argument supported by qualitative solutions ${ }^{8}$.

The final section of knowledge and application opportunity for an engineer to complete their transition as a highly valued team member is associated with cost accounting and/or basic accounting principles applied to business. Financial performance is perhaps the most decisive measurement of success associated with a given project. Management and customers alike are apt to be concerned with a project's financial margins as they are with schedule. Historically, engineers have received a somewhat negative image relative to managing financial performance. This image may be related to the concept that engineers are devoted to the inherent nature of

Proceedings of the 2001 American Society for Engineering Education Annual Conference \& Exposition Copyright (C) 2001, American Society for Engineering Education 
their work, research and design while giving the impression of being oblivious to associated costs. In industries such as defense where contracts are awarded and administered on a fixedprice basis, all project team members become well versed in cost accounting disciplines. Team members become acutely aware of the cost each effort carries as a project and its deliverable product moves through its life cycle. Thought processes evolve from one focused on "what is our budget and how can I spend it" to "how much is each one of these steps costing and how can that cost be reduced."

Of all the performance-enhancing practices an engineer could embrace to increase their value to a business, costing knowledge is perhaps the most significant. Basic cost accounting principles combined with familiarity of concepts such as Activity Based Costing (ABC) or Work Breakdown Structures (WBS's) provide the engineer with core knowledge to establish a complete, comprehensive engineering discipline. Integration of cost accounting principles and practices with core engineering disciplines establishes an inherent consideration for associated thought processes businesses need and are looking to obtain to be a competitive force in their respective marketplace. Engineering processes governed by cost accounting principles lead into such efficient engineering-driven activities such as designing for manufacturing and assembly (DFMA), failure mode effect analysis (FMEA's), designs tested by experiments (DOE's) and product / process life-cycle reliability testing'.

The intent of the proposals provided by this paper is not to compromise traditional engineering disciplines, but to compliment them. Companies have committed a significant portion of funding to upgrade skills to meet engineering system management needs using many of the tools and processes mentioned in this report. Many of these activities have had to be learned on-thejob with no prior understanding of core concepts and applications. Many of the training programs used by companies to enhance employee skills may not adequately address the given subject in a way that compliments an engineer's core knowledge and talents. It is at this point in an engineer's career development that America's engineering education programs realize the opportunity, and some may say obligation, to assist with providing a product who comes into a business with functional knowledge of all core accountabilities of an engineering operation. Graduate - level engineering studies may be the best point of development for addressing the additional skills engineers are being required to implement as part of their regular duties. Graduate programs are considered by some to be the "finishing school" for a given discipline. Students entering graduate programs already possess discipline core knowledge. Graduate course structures and formats appear to be best suited for the learning process associated with developing a "system oriented" engineer. The graduate studies community stands at an opportunistic crossroad. American industry has already defined the need through their operations, the graduate education system appears to be a viable way to meet the need.

\section{Bibliography}

1. Stamitis, D.H., (1995). Failure Mode and Effect Analysis, FMEA from Theory to Execution. Milwaukee: ASQ Press.

2. Hitt, M.A, Ireland, D.R., and Hoskisson, R.E., (2001). Strategic Management, Competitiveness and Globalization (4 ${ }^{\text {th }}$ Ed.). (pp. 209-210). Cincinnati: South-Western College Publishing.

Proceedings of the 2001 American Society for Engineering Education Annual Conference \& Exposition Copyright (O) 2001, American Society for Engineering Education 
3. Hitt, M.A, Ireland, D.R., and Hoskisson, R.E., (1999). Strategic Management, Competitiveness and Globalization (3rd Ed.). (pp. 391-427). Cincinnati: South-Western College Publishing.

4. Stamitis, D.H., (1995).

5. Mason, R.L., Gunst, R.F, and Hess, J.L., (1989). Statistical Design and Analysis of Experiments, With Applications to Engineering and Science. New York: John Wiley \& Sons.

6. Day, Ronald G., (1993). Quality Function Deployment, Linking a Company With its Customers. (pp. 1-15). Milwaukee: ASQ Press,.

7. American Society for Quality Control Standards Committee. (1995). Quality Management Guidelines for Configuration Management. (ANSI/ISO/ASQC Q10007-1995). Milwaukee: ASQ Press.

8. Brassard, M., (1989). The Memory Jogger Plus+, Featuring the Seven Management and Planning Tools. Methuen: Goal/QPC.

9. Garrison, R.H., and Noreen, E.W., (1997). Managerial Accounting ( $8^{\text {th }}$ Ed.). (pp. 4-26). Chicago: McGraw-Hill.

\section{MARK L. CROZIER}

Mark L. Crozier is currently the Quality Manager for an upper mid-west manufacturing company. Mark has over twenty years of manufacturing and engineering experience in defense industry and the commercial manufacturing sector supplying products to medical, automobile, pharmaceutical, and fire industry markets. Mark holds a BA in Management from the University of Redlands, California, an MS in Quality Assurance from the California State University Dominguez Hills, California and an MS in Manufacturing Systems from the University of St. Thomas, Minnesota. 